\title{
论文
}

\section{近7 ka来南黄海中部冷水团演化的底栖有孔虫记录}

\author{
钟福昌 ${ }^{1,2}$, 向荣 ${ }^{*}$, 杨艺萍 ${ }^{1}$, 赵美训 $^{3}$ \\ 1. 中国科学院南海海洋研究所, 中国科学院边缘海与大洋地质重点实验室, 广州 510301; \\ 2. 中国科学院大学地球科学学院, 北京 100039 ; \\ 3. 中国海洋大学, 海洋化学理论与工程技术教育部重点实验室, 青岛 266100 \\ * 通讯作者, E-mail: rxiang@scsio.ac.cn
}

收稿日期：2017-09-21; 收修改稿日期：2018-01-02; 接受日期：2018-03-21; 网络版发表日期：2018-05-08 国家重点基础研究发展计划项目(编号: 2010CB428901)、国家自然科学基金项目(批准号：41476040、91228207)和中国科学院战略先导专项 项目(编号: XDA11030104)资助

摘要 黄海中部冷水团与现代黄海环流体系密切相关, 对区域海洋环境变化有着重要的影响, 研究黄海冷水团的 变迁对理解区域环境变化机制有重要意义. 底栖有孔虫群落对底层水体环境变化响应敏感, 是底层水团重建的重 要指标. 对南黄海中部泥质区N02柱样中沉积物样品进行底栖有孔虫群落分析, 重建了南黄海中部冷水团全新世 期间的演化. 底栖有孔虫的群落结构特征及 $\mathrm{Q}$ 型因子分析结果显示全新世沉积环境可以划分为 3 个阶段: 6.9 5.0ka期间, 底栖有孔虫以Ammonia ketienziensis 为主, 指示南黄海中部冷水团为全新世最强盛期, 黄海沿岸流 对研究区域底层水体的影响较小; 5.0 2.9ka期间, Ammonia ketienziensis含量显著减少, 而Hanzawaia nipponica显 著增加, 表明南黄海中部冷水团较前一阶段有所减弱, 其影响范围有减小趋势, 相应的黄海沿岸流对研究区域底 层水体的影响略有加强但影响依然较小; 2.9ka以来, 指示黄海沿岸流的低温、低盐属种Protelphidium tuberculatum 和Buccella 属分子开始较多出现, 反映了黄海沿岸流对研究区域底层水体的影响显著增强, 而南黄海中部冷水 团则为 $7 \mathrm{ka}$ 来最弱阶段. 整体上, 全新世南黄海中部冷水团和沿岸流对研究区底层水体的影响呈此消彼长的关系. 南黄海中部冷水团在全新世期间的波动演化可能是区域气候因素(ENSO、东亚冬季风及北半球太阳辐射量变化 等)在不同时期以不同的配置综合作用于南黄海区域的结果.

关键词底栖有孔虫, 南黄海中部冷水团, 中晚全新世, ENSO, 东亚冬季风

\section{1 引言}

南黄海中部冷水团是中国近海水文中最突出且重 要的海洋现象之一(Guan, 1994; Su和Weng, 1994; 苏纪 兰, 2005; 乔方利, 2012; Mei等, 2016). 作为黄海现代环 流体系重要的组成部分, 黄海冷水团横跨近 4 个经度,
纵跨近 5 个纬度, 其范围在夏季约占据了 $1 / 3$ 的黄海深 层区域(Su和Weng, 1994), 几乎可以影响到黄海整个 海域(李昂，2016), 对区域物质输运沉积(杨子府等, 1998; Mei等, 2016; 李铁刚等, 2000)、底栖生物分布 (Wang等，2014; Xu等，2016)、水体环境变化( $\mathrm{Li}$ 等, 2015; Park等, 2011)以及渔业资源(Cho，1982; 夏长水, 
2014)等都有深远影响. 自20世纪30年代Uda(1934)发 现黄海冷水团的存在以来, 现代黄海冷水团的形成机 制、环流结构以及季节和年际变化一直受到国内外海 洋学者的广泛关注(赫崇本等, 1959; 管秉贤, 1963; Su 和Weng, 1994; 袁业立和李惠卿, 1993; 于非等, 2006; Park等, 2011).

同时，作为中国东部陆架海重要的古海洋现象之 一, 地质历史时期黄海冷水团的形成与演化规律对理 解黄海古海洋环境变化机制具有重要意义，因此黄海 冷水团在长时间尺度上的演化历史、环境效应及其控 制因素一直是中国东部陆架海区域古海洋环境研究的 重点(梅西等, 2013; 李绍全等, 1997; 杨子度等, 1998; Kim和Kucera, 2000; 李铁刚等, 2000; Mei等, 2016; 王昊 寅等，2013). 杨子㥷等(1998)通过对南黄海 $\mathrm{QC}_{2}$ 孔中微 体古生物群落的研究探讨了末次间冰期(128 75ka BP) 南黄海古冷水团沉积特征. Liu等(2010)通过对南黄海 西部的SYS0701、SYS0702和SYS0803钻孔沉积物中 的微体古生物进行分析认为, 底栖有孔虫冷水种以及 介形虫冷水种在MIS5 期早期高海平面时的出现可能 指示了黄海古冷水团在这一时期已经存在. Mei等 (2016)通过对南黄海北部DLC70-3孔的研究, 进一步 利用底栖有孔虫、长链不饱和烯酩、总有机质含量、 总硫含量以及Mo元素等指标重建了中更新世至全新 世早期黄海古冷水团的演化历史，并指出地质历史时 期黄海古冷水团间歇性的演化模式主要受到海平面变 化以及区域构造沉降等因素的控制. 然而, 对于中全新 世黄海现代环流体系建立以来黄海冷水团的相关研究 目前仅初步探讨了其形成时间(刘健等，1999; 李铁刚 等, 2000; Kim和Kucera, 2000), 对现代黄海冷水团形成 后的演化规律及影响机制不甚了解, 相关研究亟待 加强.

南黄海中部存在一个巨厚的泥质沉积区, 它的形 成与黄海现代环流体系, 尤其是黄海冷水团的存在有 着密切的关系(Zhao等, 1990; Park和Khim, 1992; 李铁 刚等, 2000). 同时, 作为高沉积速率的稳定沉积体, 它 详细地记录了黄海暖流、黄海冷水团与黄海沿岸流等 黄海环流体系以及东亚冬季风、ENSO等气候因素在 全新世期间的波动演化及其对南黄海区域环境演化的 影响, 是研究过去海洋环境和气候变化的绝佳档案库 (Moreno和Canals, 2004), 同时也是研究全新世黄海冷 水团历史变迁的理想材料.
底栖有孔虫作为生活在海底沉积物表层中的环境 敏感型生物体, 其群落组合及分布特征主要是受其赖 以生存的底层水体环境的控制(向荣等，2003a)，不同 属种对底层水团中温度、盐度等环境要素的适应性不 同. 因此, 底栖有孔虫群落结构特征的变化可以较好地 反映底层水体环境变化, 是底层水团重建的重要指标 (向荣等, 2003b). 因此, 利用南黄海中部泥质沉积区内 沉积物中的底栖有孔虫的群落结构特征可以重建全新 世期间黄海底层水团, 即黄海冷水团的演化历史, 进而 探讨其对区域气候因素的响应.

本文选取的研究材料是取自南黄海中部泥质区西 北侧的N02孔(图1), 该孔位于黄海中部冷水团范围的 边缘(苏纪兰, 2005; 乔方利, 2012), 且沉积记录连续, 是探讨千年尺度上黄海冷水团变迁的理想站位. 我们 拟通过对该沉积物柱样中底栖有孔虫进行 $\mathrm{AMS}^{14} \mathrm{C}$ 测 年、群落特征分析，重建中全新世黄海现代环流体系 建立以来黄海冷水团的演化历史，探讨其演化过程对 不同区域气候因素变化的响应，并初步探讨全新世期 间控制黄海冷水团演变的影响机制, 为南黄海古海洋 环境研究提供基础性资料, 进一步推进全新世黄海沉 积环境变化研究.

\section{2 水文环境}

南黄海是半封闭的浅陆架海, 位于中国大陆和朝

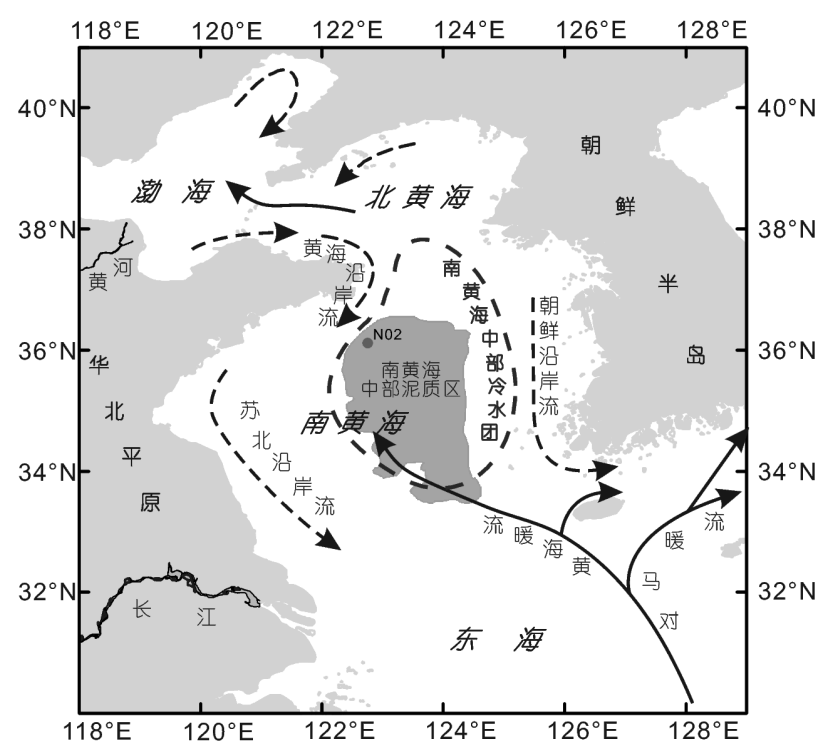

图 1 取样站位、南黄海中部泥质区、中国东部海域环流 示意图、南黄海中部冷水团范围

分别改自Li等(2014)、苏纪兰(2005)、Kim和Kennett(1998) 
鲜半岛之间, 水深大多小于 $100 \mathrm{~m}$. 在长江、黄河每年 大量的径流输入的影响下, 南黄海的盐度总体较低 $(<32 \%$ ) , 其海水具有半咸水的特征(秦蕴珊等，1989), 但盐度季节变化较大, 冬春盐度较高, 夏秋盐度较低. 其盐度还受南黄海海水与开放大洋水体的交换程度, 即黄海暖流的影响(Kim和Kennett, 1998; Kim和Kucera, 2000; Kong等, 2006). 现代南黄海的环流体系主 要包括黄海暖流和沿岸流系, 基本流向常年较为稳定, 流速强度上有夏弱冬强的特征. 黄海暖流沿南黄海东 部边缘北上，与南下的江苏沿岸流、黄海沿岸流共同 形成南黄海逆时针(气旋)环流(Beardsley等，1985; Liu 等, 2004). 冬季, 在强烈的东亚冬季风的作用下, 水体 垂直混合作用强烈; 夏季, 在表面热辐射、潮汐混合以 及冲淡水的作用下，使得水体层化明显(Naimie等, 2001). 夏秋季节, 在南黄海中部, 存在一个低温 $\left(<10^{\circ} \mathrm{C}\right)$ 、高盐 $(32.0 \sim 33.0 \%)$ 的水团, 被称为南黄海底 层冷水团(the southern Yellow Sea cold bottom water, YSCBW; 于非等, 2006; 图1). 南黄海冷水团作为季节 性的水团, 春季它伴随着温跃层的出现而产生, 而到了 秋季它伴随着温跃层的消亡而消失(于非等, 2006).

现代物理海洋学研究表明, 黄海中部冷水团的强 弱变化则主要受到东亚冬季风及夏季太阳辐射量的影 响, 同时与ENSO也密切相关(李昂, 2016; 薛玉虎, 2014; Li等, 2015; 宋新等, 2009). 强的冬季风一方面 导致冬季海水垂向混合更充分彻底, 另一方面为南黄 海西部区域带来了更多的冷水, 两方面共同促使来年 春夏季残留的底层冷水水温较低(宋新等, 2009; 李昂, 2016); ENSO则通过夏季热通量或夏季风压场来调节 黄海中部冷水团的强弱变化( $\mathrm{Li}$ 等, 2015), 当厄尔尼诺 事件发生频次高时, 黄海冷水团的分布范围一般较小, 频次低时, 分布范围一般较大(宋新等, 2009). 此外, 全 新世长时间尺度的北半球夏季太阳辐射量的变化对黄 海中部冷水团也有影响, 北半球夏季太阳辐射量增加 会使海水表层温度上升, 温跃层上界深度变浅, 海水 层化现象加强, 进而强化了黄海中部冷水团, 使冷水 团的范围增大; 反之亦然(薛玉虎, 2014; 郭东琳, 2014).

\section{3 材料与方法}

N02柱样于2011年4月搭载中国海洋大学“东方红 2 号”科学考察船利用重力取样取自南黄海中部泥质区 $\left(122^{\circ} 39.0^{\prime} \mathrm{E}, 36^{\circ} 3.6^{\prime} \mathrm{N}\right.$, 水深64m; 图1). 岩芯全长 $298 \mathrm{~cm}$. 岩芯按照约 $4 \mathrm{~cm}$ 的间隔取样, 共获得 65 个样品. 样品首 先在 $60^{\circ} \mathrm{C}$ 恒温烘箱中烘干, 然后称取约 $50 \mathrm{~g}$ 干重, 再将 样品放入清水浸泡大约 $24 \mathrm{~h}$, 使得样品充分分散. 而后 将样品置于 $63 \mu \mathrm{m}$ 的铜篮上冲洗, 将大于 $63 \mu \mathrm{m}$ 的部分 收集、烘干, 再次称重以计算 $>63 \mu \mathrm{m}$ 的粗组分含量. 底栖有孔虫只从大于 $150 \mu \mathrm{m}$ 的粗组分中选出、鉴定并 全部计数, 然后利用 $\mathrm{Q}$ 型因子分析对底栖有孔虫相对 丰度的数据进行数理统计分析 (Klovan和Imbrie, 1971). 底栖有孔虫的属种鉴定主要参考中国东陆架海 区相关的文献资料(Wang等, 1985; 汪品先等, 1988; Lei 和 Li, 2016).

N02孔沉积物岩性上下均一, 主要为灰色或深灰 色黏土质粉砂, 全柱 $>63 \mu \mathrm{m}$ 的粗组分含量均在 $0.5 \%$ 以 下(图2). 为了获取精确的年代标尺, 从N 02 孔的 9 个层 位中挑选出混合底栖有孔虫进行 $\mathrm{AMS}^{14} \mathrm{C}$ 测年的, 挑选 的样品选送至北京大学进行测定(表1), 测年计算使用 的 ${ }^{14} \mathrm{C}$ 半衰期为 5568 年. $\mathrm{AMS}^{14} \mathrm{C}$ 测年数据利用 $\mathrm{CA}-$ LIB6.1.1程序和最新的校正曲线进行校正(Stuiver等, 1998), 得到日历年龄, 区域碳储库采用青岛和朝鲜半 岛的 3 个区域校正数据的平均值(Southon等, 2002; Kong和Lee, 2005)进行校正 $(\Delta R=(-128 \pm 35) \mathrm{a})$. 其中部 分测年数据已经发表(Hao等, 2017). 本文中使用的年 代均为日历年龄, 并用ka来代表cal.ka BP.

\section{4 结果}

\section{1 底栖有孔虫群落总体特征}

N02孔的样品中含有丰富的有孔虫, 我们从 65 个 样品中, 共挑出有孔虫个体 48468 个, 平均每个样品中 有 745 个壳体. 柱样中以底栖有孔虫为主, 总共鉴定出 35 种底栖有孔虫, 分属于 32 个属; 而浮游有孔虫数量极 少, 仅在零星层位鉴定出十几个个体. 群落中以玻璃质 壳占绝对优势, 在样品中的平均丰度达 $91.42 \%$, 砂质 壳和瓷质壳数量较少, 其平均丰度分别为 $4.38 \%$ 和 4.05\%(图3). 底栖有孔虫的绝对丰度在早期(6.9 4.0ka) 较低, 最小出现在 $241 \mathrm{~cm}$ 处, 为 128 个 $/ 50 \mathrm{~g} ; 4.0 \mathrm{ka}$ 以来绝 对丰度不断上升, 绝对丰度最大值出现在 $29 \mathrm{~cm}$ 处, 为 2586 个 $/ 50 \mathrm{~g}$. N02柱样平均沉积速率为 $42 \mathrm{~cm} \mathrm{ka}^{-1}$, 其中, 6.9 4.4ka期间沉积率较高 $\left(50 \sim 60 \mathrm{~cm} \mathrm{ka}^{-1}\right)$; 4.4 3.9ka左 右沉积速率达到最大 $\left(82 \mathrm{~cm} \mathrm{ka}^{-1}\right)$; 随后沉积速率不断 


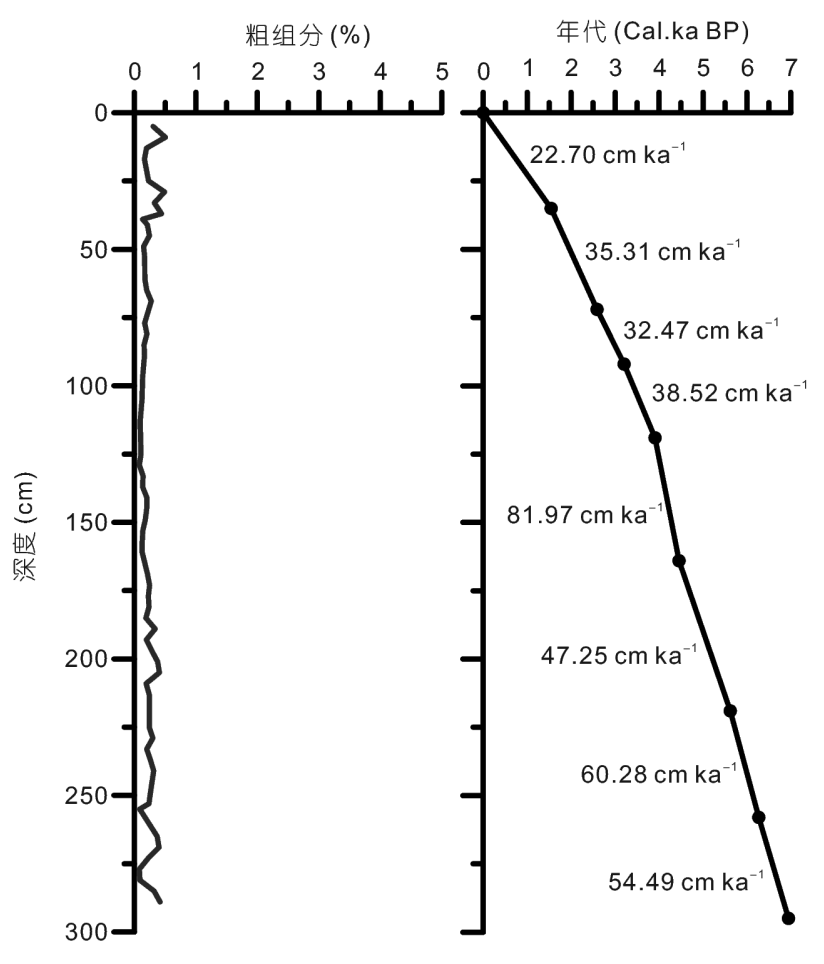

图 $2 \mathrm{~N} 02$ 孔 $>63 \mu \mathrm{m}$ 粗组分百分含量、年代框架和沉积 速率

降低, 至 $1.5 \mathrm{ka}$ 以来, 沉积速率仅 $23 \mathrm{~cm} \mathrm{ka}^{-1}$. 底栖有孔虫 丰度变化与N02柱样沉积速率的变化呈显现明显相反 (图3). 当沉积速率高的时候，底栖有孔虫绝对丰度较 低; 当沉积速率低的时候，底栖有孔虫绝对丰度较高， 这可能是由于当底栖有孔虫产率一定时，较高的沉积 速率对底栖有孔虫的堆积速率有稀释作用.

图4中展示了 N02柱样中主要的底栖有孔虫属种
的相对丰度，从总的平均相对丰度来看，N02柱样中， 以Ammonia ketienziensis和Hanzawaia nipponica最为 丰富, 平均相对丰度分别为 $28.83 \%$ 和 $20.93 \%$. A.ketienziensis 和H.nipponica 都是南黄海中部泥质区的主要分 子(Wang等, 1985; 汪品先等, 1988; Lei和Li, 2016). 其 他属种以相对丰度由高到低依次是Astrononion italicum $(6.77 \%) 、 B u l i m i n a ~ m a r g i n a t a(6.27 \%) 、 E l p h i d i u m$ advenum(4.92\%)、Protelphidium tuberculatum (4.86\%)、Gaudrynia spp.(4.31\%)、Ammonia maruhasii (4.2\%)、Triloculina spp.(3.0\%)、Buccella inusitata (2.3\%)、Lagena spp.(2.1\%)和Elphidium magellanicum (2.1\%)等.

\subsection{Q 型因子分析结果}

在不同的时期或阶段，底栖有孔虫属种常以优势 种或特征种的形式出现，这里通过对至少在 3 个样品 中相对百分含量大于 $2 \%$ 的 20 个属种进行 $\mathrm{Q}$ 型因子分 析, 并做方差最大化旋转处理, 提取了 3 个主因子, 这 3 个主因子的累积方差贡献为 $92.5 \%$. 每个主因子在不 同时期或阶段出现较高的正载荷或负载荷(图 5; 表2), 反映了 3 个主要的底栖有孔虫群落结构及其指示的沉 积环境特征. 其中主因子 1 解释了总方差的 $39.38 \%$, 主 要以H.nipponica、A.italicum、Gaudrynia spp.和A. maruhasii组合为主; 主因子 2 解释了总方差的 $40.07 \%$, 主要以A.ketienziensis、B.marginata组合为主; 主因子3 解释了总方差的 $13.05 \%$, 主要为P.tuberculatum、E.advenum、B.inusitata和E.magellanicum组合为主. 根据3 个主因子变化特征可以将南黄海中部泥质区 $6.9 \mathrm{ka}$ 以

表 $1 \quad \mathrm{~N} 02$ 柱样 $\mathrm{AMS}^{14} \mathrm{C}$ 测年数据 ${ }^{\mathrm{a})}$

\begin{tabular}{|c|c|c|c|c|c|}
\hline 样品号 & 深度(cm) & 材料 & $\begin{array}{c}\mathrm{AMS}^{14} \mathrm{C} \text { 年龄 } \\
(\mathrm{a} \text { BP) }\end{array}$ & $\begin{array}{c}\text { 日历年龄 } \\
\text { (a BP) }\end{array}$ & $\begin{array}{l}2 \sigma \text { 范围 } \\
(\mathrm{a} \mathrm{BP})\end{array}$ \\
\hline QAS0787 & $0 \sim 4(0)$ & 混合底栖有孔虫 & $305 \pm 25$ & 0 & \\
\hline QAS0788 & $34 \sim 36(35)$ & 混合底栖有孔虫 & $1855 \pm 40$ & 1542 & $1400 \sim 1683$ \\
\hline QAS0789 & $70 \sim 74(72)$ & 混合底栖有孔虫 & $2705 \pm 30$ & 2590 & $2428 \sim 2719$ \\
\hline QAS0790 & $90 \sim 94(92)$ & 混合底栖有孔虫 & $3215 \pm 35$ & 3206 & $3056 \sim 3340$ \\
\hline QAS0791 & $116 \sim 122(119)$ & 混合底栖有孔虫 & $3795 \pm 35$ & 3907 & $3760 \sim 4068$ \\
\hline QAS0792 & $162 \sim 166(164)$ & 混合底栖有孔虫 & $4195 \pm 30$ & 4456 & $4308 \sim 4594$ \\
\hline QAS0793 & 216 222(219) & 混合底栖有孔虫 & $5130 \pm 30$ & 5620 & $5519 \sim 5731$ \\
\hline QAS0794 & $256 \sim 260(258)$ & 混合底栖有孔虫 & $5720 \pm 40$ & 6267 & $6166 \sim 6389$ \\
\hline QAS0795 & $292 \sim 298(295)$ & 混合底栖有孔虫 & $6325 \pm 35$ & 6946 & $6799 \sim 7110$ \\
\hline
\end{tabular}

a) 部分测年数据已发表(Hao等, 2017) 


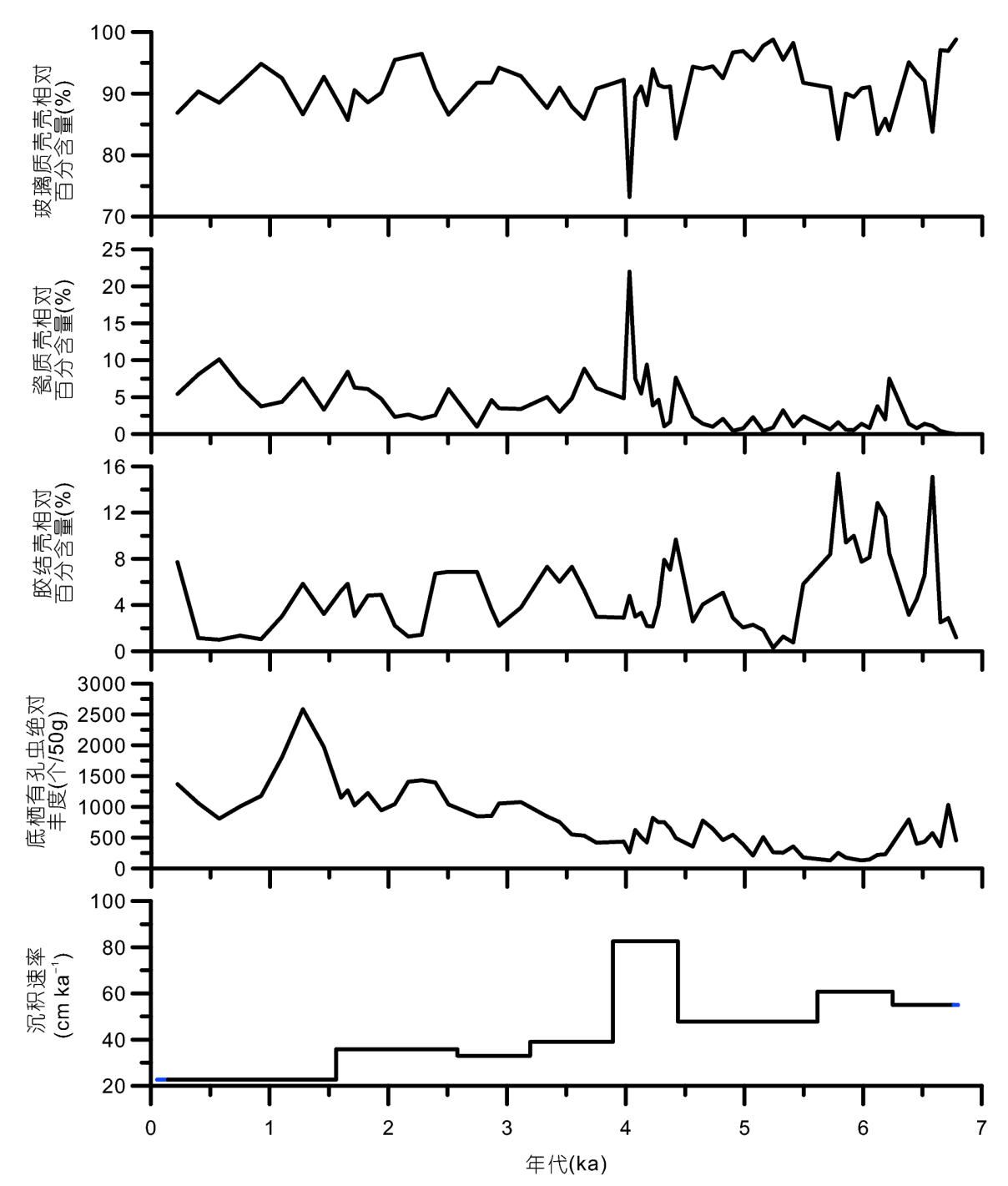

图 3 N02孔玻璃质壳、瓷质壳及胶结壳相对百分含量、底栖有孔虫绝对丰度及N02孔沉积速率

来的古环境演化分为6.9 5.0、5.0 2.9和2.9 0ka的3个 阶段(图5).

阶段 I (200 290cm; 5.0 6.9ka): 这一阶段以主因 子 2 最高的负载荷为主要特征, 其中A.ketienziensis 显示 了最高的负得分. 这一阶段的底栖有孔虫属种以南黄 海中部泥质区的主要分子A.ketienziensis 为主, 相对百 分含量达到 $50 \sim 70 \%$; 其次是 B.marginata，相对百分含 量为 $15 \sim 25 \%$. 这一时期的个别层位出现了一定量的 Uvigerina semitrigona、Pullenia quinqueloba及Bulimi$n a g i b b a$ 等属种. 这一阶段的底栖有孔虫丰度相对 较低.

阶段 II (88 200cm; 2.9 5.0ka): 这一阶段的主要特
征为主因子 1 得分快速上升、主因子 2 得分快速下降并 各自伴随着波动变化. H.nipponica的含量在这一阶段 早期有明显的上升, 而A.ketienziensis的含量在这一阶 段的早期快速下降, 相对丰度为 $30 \sim 40 \%$; E.advenum、 A.italicum 的含量增加, 相对丰度分别为 $5 \sim 8 \%$ 、 $8 \sim 14 \%$. 这一阶段的底栖有孔虫丰度缓慢增加.

阶段III (0 88cm; 0.0 2.9ka): 在这一阶段中, 主因 子 3 的得分波动上升, 而主因子 1 的得分波动下降并伴 随主因子 2 的得分呈现稳定低值的特征. A.ketienziensis 的含量在这一阶段较为稳定, H.nipponica的含量在这 一阶段波动下降, 而代表低温低盐属种P.tuberculatum、E.advenum、B.inusitata和E.magellanicum 的相对 


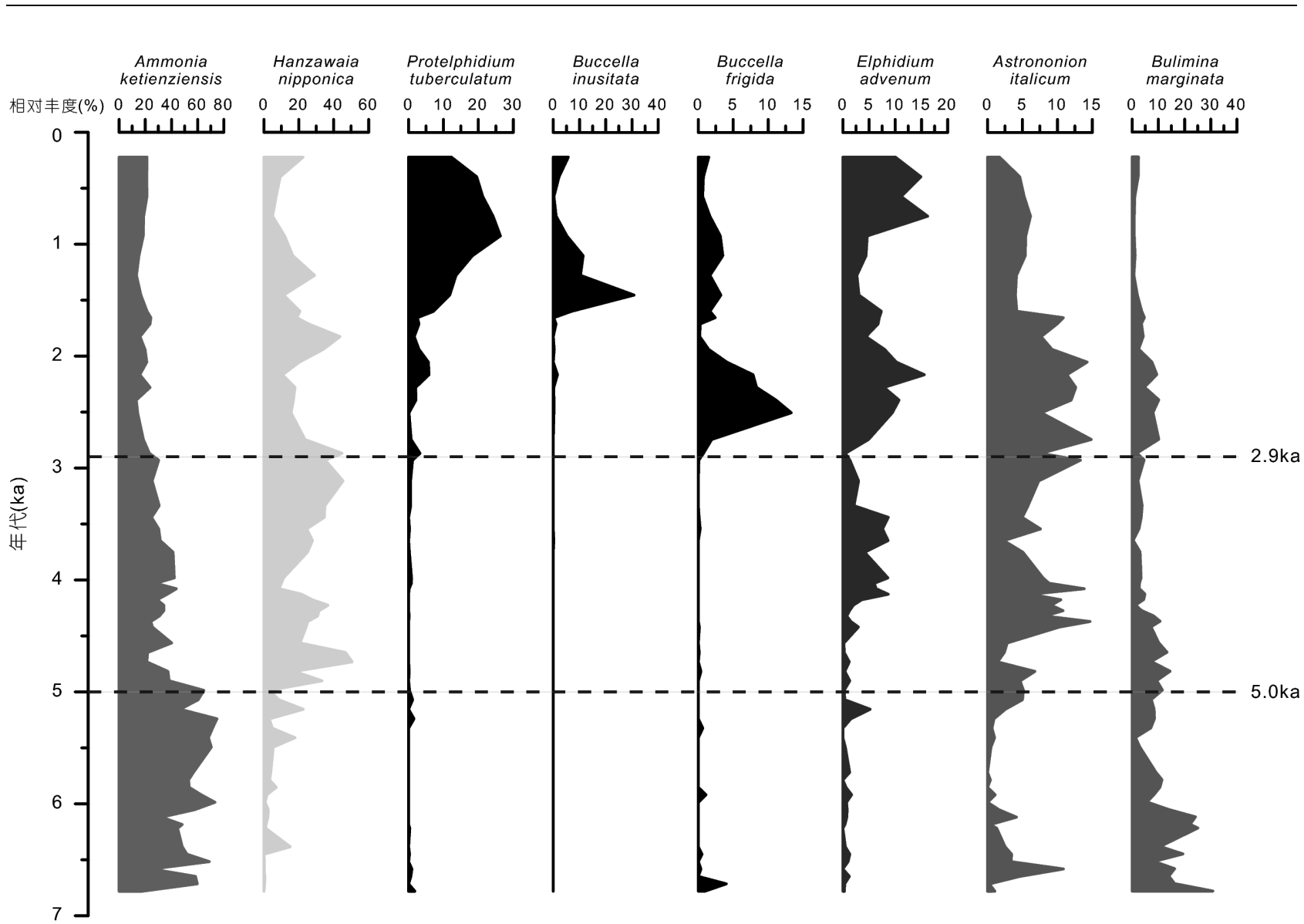

图 4 N02柱样中底栖有孔虫主要属种的相对丰度 $(\%)$

百分含量在这一阶段达到最高，这些属种的总含量为 20 40\%. 底栖有孔虫的丰度在这一阶段含量较高, 平 均丰度大于 1200 个 $/ 50 \mathrm{~g}$.

\section{5 分析与讨论}

\section{1 黄海中部冷水团演化的现状与指标}

尽管在黄海区域开展了许多关于南黄海全新世古 环境演化的研究，但是大多集中于早中全新世的环境 变化研究, 尤其是对现代环流体系的重要组成部分黄 海暖流及黄海中部冷水团形成时间的研究，而对于现 代环流体系形成后南黄海环流体系的波动演化研究较 少, 有研究还认为高海平面形成以来黄海沉积环境较 为稳定 (Kim等， 1999). 但是，从底栖有孔虫群落组合 上的变化(图4)可以看出高海平面形成以后, 黄海环流 体系是存在阶段性的波动和演化的. 底栖有孔虫群落 分布主要受到底层水体的影响并且对环境响应敏感,
底栖有孔虫的群落组合演变与底层水团的演化密切相 关. 这里, 我们主要基于对南黄海现代底栖有孔虫群落 特征的认识来建立黄海中部冷水团和黄海沿岸流的相 关替代性指标.

现代黄海中部冷水团区域内底栖有孔虫群落以 $A$. ketienziensis和H.nipponica 占绝对主导优势为主要特征 (Wang等, 1985; Xiang等, 2008), 我们可以通过分析这 两个属种的群落特征变化来追踪冷水团演化(Fang等, 2013). 其中, A.ketienziensis生存于水深大于50m中陆架 海区，生存的盐度范围较高(32 33\%), 而生活的温度 与Ammonia compressiuscula、H.nipponica相比相对较 低(Fang等, 2013; Lei和Li, 2016), 其相对丰度在黄海中 部冷水团中心位置可达到 $80 \%$ (Xiang等, 2008), 越往边 缘位置其相对丰度越低(Wang等，1985). 在本研究中, 我们将其相对丰度作为黄海中部冷水团强弱变化的指 标, 指示黄海中部冷水团范围的扩大或缩小. 当黄海中 部冷水团较为强盛时, 黄海中部冷水团范围较大, N02 


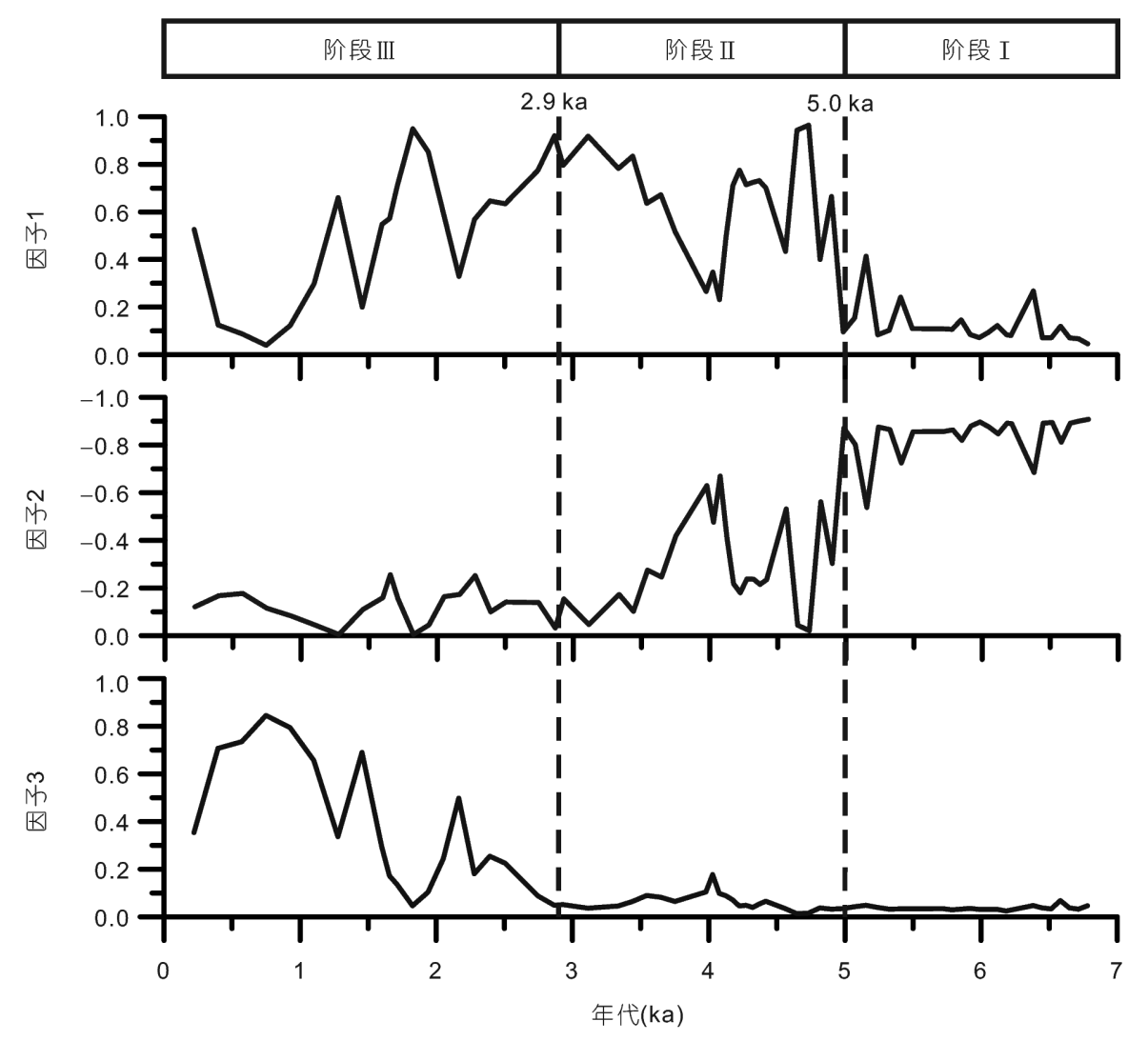

图 $5 \mathrm{~N} 02$ 柱样中底栖有孔虫3个主因子方差最大化因子载荷随年代变化曲线

站位受黄海中部冷水团中心影响较大, A.ketienziensis 的相对丰度高; 反之亦然. H.nipponica生存于水深大 于 $50 \mathrm{~m}$ 中陆架海区, 生存的盐度范围较高(32 33\%o), 也是现今南黄海中部泥质区的主要分子(Wang 等, 1985; Fang等, 2013; Lei和Li， 2016). 但是相对于 $A$. ketienziensis 来说, H.nipponica生活的水温可能略高一 些(Fang等, 2013; Lei和Li, 2016; 方力, 2013), 其相对 百分含量的增加可能反映了该站位受黄海中部冷水团 的影响减弱导致该站位附近海域底层水略有升温. 除 了这两个黄海中部冷水团的典型属种以外，一些低温 低盐属种的变化也可以间接指示黄海中部冷水团的变 化. E.advenum生存的水深范围较广, 但在近岸低盐海 域的含量最高(Wang等, 1985; 汪品先等, 1988), 其相对 丰度的增加可以反映水团中盐度的减小; P.tuberculatum 是黄海沿岸流分布区的主要分子，其在南黄海西 北部的生态分布主要受到低温低盐的黄海沿岸流的影 响(汪品先等, 1988), B.frigida、B.inusitata和E.magellanicum 也是典型的低温低盐属种(汪品先等, 1988; Kang
等, 2010). 本研究中, 利用这一低温低盐属种的群落组 合(P.tuberculatum、E.advenum、B.frigida、B.inusitata 和E.magellanicum) 指示该位置受黄海沿岸流影响的程 度, 黄海沿岸流影响的程度越大, 低温低盐属种的含量 越高.

\section{2 近 $7 \mathrm{ka}$ 来黄海中部冷水团演化}

根据替代性指标重建的近 $7 \mathrm{ka}$ 来黄海冷水团的演 化可以分为以下三个阶段:

6.9 5.0ka期间(阶段 I ) 底栖有孔虫群落组合以较 高的A.ketienziensis 含量伴随着较低丰度的低温低盐属 种为主要特征(图4), 表明该位置附近的海域受黄海中 部冷水团的影响较大, 而受黄海沿岸流的影响较小, 指 示中全新世晚期黄海中部冷水团较为强盛, 其中心范 围可能大于现今冷水团的中心范围.

5.0 2.9ka期间(阶段 II ), 从Q型因子分析的结果中 看到主因子 1 与主因子 2 的变化趋势出现快速替换(图 5), 相对应的底栖有孔虫的组合也发生了明显的变化 
表 2 N02柱样中 20 种底栖有孔虫在 3 个主因子上的方差最大化因子得分 ${ }^{\mathrm{a})}$

\begin{tabular}{|c|c|c|c|}
\hline 属种 & 主因子 1 & 主因子2 & 主因子3 \\
\hline Ammonia ketienziensis & 1.063 & -4.094 & 0.725 \\
\hline Hanzawaia nipponica & 4.148 & 1.219 & 0.171 \\
\hline Elphidium advenum & 0.091 & 0.279 & 1.863 \\
\hline Ammonia maruhasii & 0.353 & -0.138 & 0.502 \\
\hline Bulimina marginata & 0.233 & -1.023 & -0.122 \\
\hline Buccella frigida & 0.051 & 0.14 & 0.651 \\
\hline Buccella inusitata & -0.162 & 0.236 & 1.186 \\
\hline Astrononion italicum & 0.8 & 0.153 & 0.814 \\
\hline Elphidium magellanicum & -0.204 & 0.139 & 1.172 \\
\hline Protelphidium tuberculatum & -0.679 & 0.461 & 3.318 \\
\hline Cribrononion subincertum & 0.018 & 0.008 & 0.111 \\
\hline Bulimina gibba & -0.139 & -0.147 & 0.279 \\
\hline Nonionella stella & -0.023 & 0 & 0.092 \\
\hline Gaudrynia spp. & 0.393 & -0.368 & 0.087 \\
\hline Fissurina spp. & 0.15 & -0.148 & 0.13 \\
\hline Lagena spp. & 0.19 & -0.175 & 0.074 \\
\hline Lenticulina spp. & 0.176 & -0.219 & -0.039 \\
\hline Sigmoilopsis spp. & 0.049 & -0.05 & 0.179 \\
\hline Triloculina spp. & 0.205 & 0.124 & 0.819 \\
\hline Uvigerina spp. & -0.024 & -0.04 & 0.003 \\
\hline Variance $(\%)$ & 39.38 & 40.07 & 13.05 \\
\hline Cumulative variance(\%) & 39.38 & 79.45 & 92.50 \\
\hline
\end{tabular}

a) 每个主因子中主要属种的方差因子得分用加粗字体表示

(图4), 反映出这一时期发生了较大的环境转换. 这一 时期H.nipponica含量突然增大而后波动上升伴随着 $A$. ketienziensis含量突然减少而后缓慢的波动下降，可能 反映了这一时期该位置附近受到黄海中部冷水团的影 响减弱, 从年均的角度来看温度略有上升的趋势, 表明 这一时期黄海中部冷水团减弱, 黄海中部冷水团中心 范围开始减小. 此外, 近岸低盐种E.advenum 开始出现 但含量较低, 表明黄海沿岸流开始影响该区域, 但强度 较小.

$2.9 \mathrm{ka}$ 以来(阶段III)以P.tuberculatum、B.frigida、 E.advenum、B.inusitata和E.magellanicum低温低盐属 种含量增加, 同时伴随着A.ketienziensis 含量较为稳定 且前一阶段低以及H.nipponica含量波动下降为特征 (图4), 表明该时期黄海沿岸流对研究区域的影响增强, 黄海中部冷水团强度减弱, 冷水团中心范围进一步缩 小, 其对研究区的影响显著减弱.
总的来说, 近 $7 \mathrm{ka}$ 以来, 黄海冷水团强度及其对研 究区域的影响呈现不断减弱的趋势, 而黄海沿岸流对 研究区域的影响逐渐增强. 黄海冷水团与黄海沿岸流 对研究区底层水体影响呈现出此消彼长的作用. 前人 研究发现黄海冷水团的强度主要受到东亚冬季风变化 的影响, 东亚冬季风在中全新世期间较为强盛, 而后便 呈现不断减弱的趋势(胡邦琦等, 2012; Wang等, 2012; $\mathrm{Jia}$ 等, 2015). 我们认为全新世期间南黄海底层水体的 演化并不是简单受单一水团如黄海沿岸流控制的，而 是受到黄海冷水团与黄海沿岸流的共同作用. 这也就 解释了为何黄海沿岸流对南黄海底层水体的影响逐渐 增强与黄海沿岸流自身呈现不断减弱的变化趋势不 一致.

全新世黄海冷水团或者说现代黄海环流体系的形 成时间也是全新世黄海冷水团演化研究的关注的重点 之一. 前人针对此问题开展大量了的研究, 提出了不同 
的观点. 刘健等(1999)根据YDSP102孔中冷水种Buccella frigida的含量在 $6 \mathrm{ka}$ 开始增加, 认为南黄海东南侧 的冷水团形成于 $6 \mathrm{ka}$ 左右. Kim和Kucera(2000)根据 8.47 6.63ka期间 CC02和CC04孔中底栖有孔虫优势属 种由Ammonia beccarii替换为由 $A$. ketienziensis认为现 代黄海环流体系建立于 8.47 6.63ka期间; Kong等 (2006)通过对南黄海东南侧的YDSP103孔中底栖有孔 虫群落特征及Cibicides lobarulus的氧同位素数据分析 认为现代黄海环流体系形成于 $4.3 \mathrm{ka}$ 左右; Xiang等 (2008)根据南黄海中部泥质区中部的YE-2孔在 $6 \sim 5 \mathrm{ka}$ 期间, 底栖有孔虫优势属种由 A. aomoriensis替换为 $A$. ketienziensis, 并伴随着粒度和同位素数值的较大变化, 认为现代黄海环流体系建立于 $6 \sim 5 \mathrm{ka}$ 期间; 而Fang等 (2013)根据C02孔中底栖有孔虫优势属种在7.7 6.2ka 期间由A.compressiuscula替换为A.ketienziensis, 认为现 代黄海环流体系的建立开始于7.7 6.2ka期间, 黄海暖 流与黄海冷水团最终形成于 $6.2 \mathrm{ka}$ 左右. 在本研究中, 由于 $\mathrm{N} 02$ 孔取样深度有限, 并未打穿泥质沉积体, 因此 无法确定该区域全新世泥质沉积形成时间, 也无法确 定黄海冷水团及与其密切相关的黄海暖流形成并影响 到该区域的时间. 但是, 根据N02孔底部的底栖有孔虫 群落组合以A.ketienziensis 占绝对优势为主要特征, 结 合前人的关于底栖有孔虫优势属种由 A.compressiuscu$l a$ 替换为A.ketienziensis指示黄海中部冷水团形成的认 识(Kim和Kennett, 1998; Kim和Kucera, 2000; Xiang等, 2008; Fang等, 2013), 推测研究区域受到黄海中部冷水 团影响的时间可能早于 $6.9 \mathrm{ka}$, 这一推测与前人的认识 略有不同. 我们初步分析认为产生这一差异的原因可 能有两个: 第一, 来自不同研究者的岩芯在年代测试 方面可能存在差异; 第二, 全新世期间黄海古海洋环 境演化可能存在区域差异. 具体原因还需要更多具有 高精度年代框架的资料来证实.

\section{3 近7 ka来黄海中部冷水团演化的驱动因素}

近 $7 \mathrm{ka}$ 来黄海中部冷水团演化与黄海现代环流体 系的发展演化密切相关. 而全新世期间南黄海环流体 系的波动演化可能是区域气候因素(ENSO、东亚冬季 风及北半球太阳辐射)在不同时期以不同的配置综合 影响黄海环流体系进而作用于南黄海区域的结果.

6.9 5.0ka期间, 南黄海中部泥质区粒度指标(胡邦 琦等，2012；图6a)、耀县黄土粒度指标(Xia等，2014;
图6b)和中国南部湖光岩玛珥湖的硅藻记录(Wang等, 2012; 图6c)共同指示东亚冬季风较为强盛, 同时北半 球夏季太阳辐射量在这一时期达到最大(Berger和Loutre, 1991; 图6d), 与黄海冷水团在这一时期较为强盛相 对应(图6f). 强劲冬季风一方面使得沿岸流加强(乔方 利, 2012), 为南黄海西部区域带来了更多的冷水(李 昂, 2016); 另一方面使南黄海区域冬季海水垂向混合 更充分彻底, 为底层水体带去更多冷水(Hur等, 1999), 而黄海冷水团主要是来源于冬季底层水体的残留水 (赫崇本等, 1959; Guan, 1994), 因此由强冬季风造成的 强混合过程会使黄海中部冷水团势力较为强盛(翁学 传等, 1989; Hur等, 1999; 宋新等, 2009; 李昂, 2016). 而 北半球夏季太阳辐射量达到最大值使得夏季南黄海水 体层化现象得到加强, 使冷水团的范围增大, 进一步强 化了黄海中部冷水团(薛玉虎, 2014; 郭东琳, 2014). 以 上两个因素共同叠加导致这一时期 02 孔附近海域底 层水受黄海中部冷水团影响明显加强. 虽然冬季风的 加强导致沿岸流在这一时期最强劲, 但由于冷水团与 沿岸流对研究区底层水体的影响为此消彼长的关系, 这一时期黄海沿岸流对研究区底层水体的影响较小, 在N02孔中体现为低温高盐属种 A. ketienziensis 成为占 绝对优势的主要属种, 而低温低盐属种含量很低.

大约 $5 \mathrm{ka}$ 期间, 热带辐合带南移, 北半球夏季太阳 辐射量的逐渐减少(Berger和Loutre, 1991; 图6d). 同时, 根据全新世ENSO的相关记录(Rodbell等, 1999; Moy 等, 2002; Conroy等, 2008; Wang等, 2012), 厄尔尼诺 活动的发生频次在 $5.0 \mathrm{ka}$ 左右明显增加(Wang等, 2012; 图6e). 此外, 耀县黄土粒度指标和中国南部湖光岩玛 珥湖的硅藻和总有机碳等记录表明, 在这一时期冬季 风出现了由强变弱的转换(Xia等, 2014; Wang等, 2012). 这些记录与N02孔底栖有孔虫群落组合的快速 变化有很好的对应(图6), 反映出这一时期在区域气候 因素配置模式方面发生了较大的转换, 同时也表明南 黄海中部泥质区的环境变化对区域气候因素配置的调 整有良好的响应.

$5.0 \sim 2.9 \mathrm{ka}$ 期间，厄尔尼诺活动频次增多(Moy等, 2002)、东亚冬季风逐渐减弱(胡邦琦等, 2012; Wang 等, 2012; Jia等, 2015; 王琳沝, 2014)、北半球夏季太 阳辐射量的逐渐减少(Berger和Loutre, 1991), 与黄海冷 水团逐渐减弱有较好的对应(图6f). 厄尔尼诺活动通过 夏季热通量和风压场的方式影响黄海中部冷水团 $(\mathrm{Li}$ 


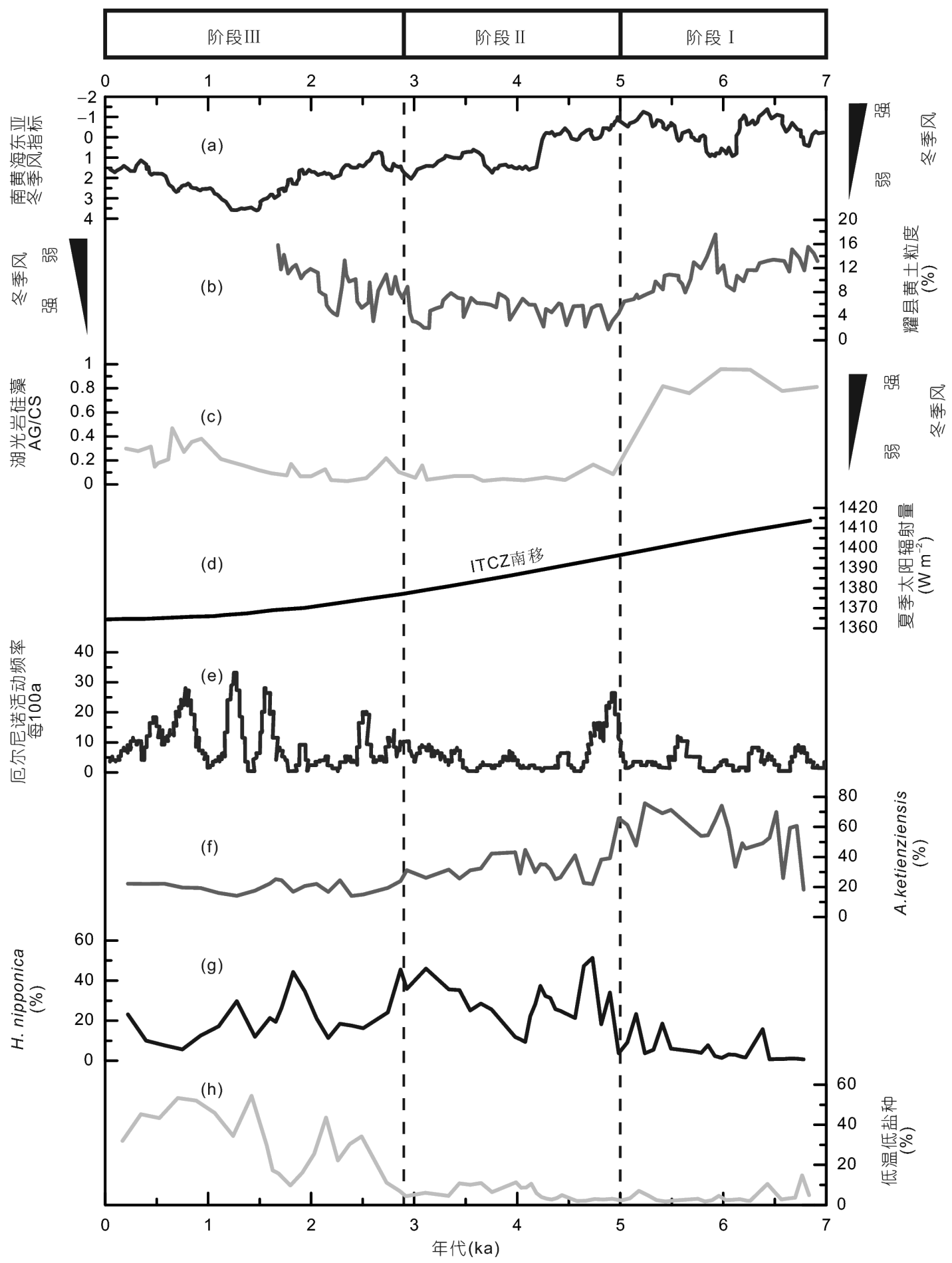

图 6 N02孔底栖有孔虫特征属种的相对丰度与东亚冬风记录、厄尔尼诺活动频率及北半球夏季太阳辐射量对比图 (a) 利用南黄海中部泥质区ZY2和ZY3孔中敏感粒级组分重建的东亚季风变化(胡邦琦等, 2012); (b) 耀县黄土粒度组分中 $>30 \mu m$ 的百分含量 (Xia等, 2014); (c) 湖光岩玛珥湖硅藻Aulacoseira granulata和Cyclotella stelligera比值(Wang等, 2012); (d) $20^{\circ} \mathrm{N}$ 的夏季太阳辐射量变化(Berger和 Loutre, 1991); (e) 每100年的厄尔尼诺活动频率(Moy等, 2002); (f) N02孔中A.ketienziensis的相对丰度; (g) N02孔中H.nipponica的相对丰度; (h) N02孔中低温低盐属种(P.tuberculatum、E.advenum、B.frigida、B.inusitata和E.magellanicum) 的相对丰度之和 
等, 2015). 当厄尔尼诺活动频次增加时, 南黄海区域从 大气进入海洋的热通量增加, 导致黄海中部冷水团范 围减小、温度上升, 进而使黄海中部冷水团减弱 $(\mathrm{Li}$ 等, 2015; 宋新等, 2009). 而冬季风的减弱使南下的冷 水减少, 同时冬季海水垂向混合过程减弱, 导致黄海中 部冷水团减弱(宋新等, 2009; 李昂, 2016). 北半球夏季 太阳辐射量的减少弱化了南黄海表层水体夏季层化现 象, 也导致黄海中部冷水团减弱(薛玉虎, 2014; 郭东 琳，2014). 这三个因素共同叠加使得黄海中部冷水团 范围减小, 进而对研究区底层水体的影响减小, 而黄海 沿岸流对研究区域的影响虽然有所增加但影响依然较 小. 这一阶段研究区附近海域底层水温度略有上升, 促 使生存温度相对较高的H.nipponica大量爆发, 而相对 低温属种A.ketienziensis的含量快速下降. 此外, ENSO 活动频次存在周期性变化, 当厄尔尼诺活动频次较低 (高)时, 黄海中部冷水团得到加强(减弱), 导致中部冷 水团对研究区的影响增强(减弱), 使得A.ketienziensis 与H.nipponica 的相对丰度也呈显出波动变化(图6 $\mathrm{f}$ 和 $6 \mathrm{~g}$ ).

$2.9 \mathrm{ka}$ 以来, 厄尔尼诺活动进一步加强(图6e; Moy 等, 2002); 冬季风相对前一阶段略有增强, 但总体上相 对较弱(图6a c; Wang等, 2012; Xia等, 2014; 胡邦琦等, 2012; 王琳沝, 2014); 北半球夏季太阳辐射量的较低 (图6d; Berger和Loutre, 1991), 与黄海冷水团进一步减 弱、黄海沿岸流显著加强相对应(图6f h). 厄尔尼诺活 动频次的进一步增加, 使得南黄海区域从大气进入海 洋的热通量进一步增加, 导致黄海中部冷水团范围进 一步减小、温度进一步上升( $\mathrm{Li}$ 等, 2015; 宋新等, 2009), 进而使得黄海中部冷水团进一步减弱(薛玉虎, 2014; 郭东琳, 2014). 同时, 较低的北半球夏季太阳辐 射量也使得黄海中部冷水团进一步较弱. 虽然在这一 时期冬季风略有增强使得黄海沿岸流和黄海中部冷水 团略有加强, 但是厄尔尼诺活动频次增加对黄海中部 冷水团的减弱作用大于冬季风的影响. 这些因素的共 同叠加导致黄海中部冷水团显著减弱. 同时, 受冷水 团与沿岸流对研究区底层水体影响此消彼长的作用, 黄海沿岸流对研究区底层水体的影响明显增强, 使低 温高盐属种A.ketienziensis 含量降低且高盐暖水种 $H$. nipponica 的相对丰度波动下降, 而低温低盐的群落组 合的相对丰度显著上升 (图6f $\sim \mathrm{h}$ ).

综上所述，中晚全新世期间南黄海中部冷水团的
演化主要受到东亚冬季风和ENSO的控制，同时还受 到北半球太阳辐射量的影响. 在早期, 强劲的冬季风 可导致沿岸流和冷水团都较强, 但由于冷水团较强, 沿岸低温低盐水团对底栖群落的影响较小; 到了 $2.9 \mathrm{ka}$ 以来, 随着ENSO的增强和北半球夏季太阳辐射量的 减小, 导致冷水团范围收缩, 虽然此时冬季风相对弱, 但是由于冷水团变弱, 故此阶段沿岸水团对底栖群落 的影响明显增强. 南黄海中部泥质区西北侧底栖有孔 虫群落特征阶段性变化及其所反映的南黄海沉积环境 演化, 对这些区域气候因素不同时期的不同配置有较 好的响应. 但是关于黄海冷水团形成、扩张、收缩方 面的研究, 还需要大范围多岩芯、多断面资料的研究 对比, 以及冷水团温度、盐度方面的指标来进一步的 研究证实.

\section{6 结论与展望}

黄海中部冷水团与现代黄海环流体系密切相关, 对区域海洋环境变化有着重要的影响, 研究黄海冷水 团的变迁对理解区域环境变化机制有重要意义. 生活 在表层沉积物中的底栖有孔虫的群落特征主要受到底 层水体环境变化的影响. 根据N02孔沉积物中底栖有 孔虫的群落结构特征以及 $\mathrm{Q}$ 型因子分析结果, 利用底 栖有孔虫冷水团替代指标首次重建了 $7 \mathrm{ka}$ 来南黄海中 部冷水团的阶段性演化序列: 6.9 5.0ka期间, 黄海中部 冷水团较为强盛, 其范围可能大于现今黄海中部冷水 团的范围, 对研究区域底层水体影响较大, 黄海沿岸 流对研究区域底层水体的影响小; 5.0 2.9ka期间, 黄 海中部冷水团减弱, 其范围有减小的趋势, 且可能存 在一定的周期变化, 对研究区域底层水体影响减弱, 而黄海沿岸流对研究区域的影响虽然有所增加但依然 较小; $2.9 \mathrm{ka}$ 以来, 黄海中部冷水团对研究区的影响显 著减弱, 而黄海沿岸流对研究区域底层水体的影响显 著增强. 总之, 全新世黄海中部冷水团和沿岸流对研 究区底层水体的影响呈现此消彼长的关系.

南黄海中部泥质区全新世高海平面以来的海洋环 境演化与黄海现代环流体系的发展演化密切相关. 全 新世期间南黄海沉积环境的波动演化可能是区域气候 因素(ENSO、东亚冬季风及北半球太阳辐射)在不同 时期以不同的配置综合影响黄海环流体系进而作用于 南黄海区域的结果. 南黄海中部泥质区西北侧底栖有 
孔虫群落特征阶段性变化及其所反映的南黄海沉积环 境演化，对这些区域气候因素不同时期的不同配置有 较好的响应. 然而, 区域气候因素的配置在中国陆架 海不同区域的响应仍有待进一步的研究. 同时，关于 全新世期间南黄海沉积环境阶段性演化方面的研究, 还需要大范围多岩芯、多断面资料的研究对比，以及 温度、盐度方面的指标来进一步的研究证实.

致谢衰心感谢国家重点基础研究发展计划“我国陆架 海生态环境演变过程、机制及未来变化趋势预测” 春季 航次为本研究提供的样品.

\section{参考文献}

方力. 2013. 南黄海全新世古海洋环境演化的底栖有孔虫记录. 硕士 学位论文. 广州: 中国科学院大学(中国科学院南海海洋研究所). 70

管秉贤. 1963. 黄海冷水团的水温变化以及环流特征的初步分析. 海 洋与湖沼, 4: 255-284

郭东琳. 2014. 黄海冷水团季节性变化的数值模拟. 硕士学位论文. 青岛: 中国海洋大学. 68

赫崇本, 汪园祥, 雷宗友, 徐斯. 1959. 黄海冷水团的形成及其性质的 初步探讨. 海洋与湖沼, 1: 11-15

胡邦琦, 杨作升, 赵美训, Satio Y, 范德江, 王利波. 2012. 南黄海中部 泥质区7200年以来东亚冬季风变化的沉积记录. 中国科学: 地球 科学, 42: 1568-1581

李昂. 2016. 黄海冷水团年际变化研究. 博士学位论文. 青岛: 中国科 学院大学(中国科学院海洋研究所). 98

李绍全, 刘健, 王圣洁, 杨子廖. 1997. 南黄海东侧陆架冰消期以来的 海侵沉积特征. 海洋地质与第四纪地质, 17: 1-12

李铁刚, 李绍全, 苍树溪, 刘健, Chang J H. 2000. YSDP102钻孔有孔 虫动物群与南黄海东南部古水文重建. 海洋与湖沼, 31: 588-595 刘健, 李绍全, 王圣洁, 杨子柫, 葛宗诗. 1999. 末次冰消期以来黄海 海平面变化与黄海暖流的形成. 海洋地质与第四纪地质, 19: 1930

梅西, 张训华, 李日辉. 2013. 南黄海北部晚第四纪底栖有孔虫群落 分布特征及对古冷水团的指示. 地质论评, 59: 1024-1034

乔方利. 2012. 中国区域海洋学, 物理海洋学. 北京: 海洋出版社. 481 秦蕴珊, 赵一阳, 陈丽蓉, 赵松龄. 1989. 黄海地质. 北京: 海洋出版社. 289

宋新, 林霄沛, 王悦. 2009. 夏季黄海冷水团的多年际变化及原因浅 析. 广东海洋大学学报, 29: 59-63

苏纪兰. 2005. 中国近海水文. 北京: 海洋出版社. 367

汪品先. 1988. 东海底质中的有孔虫和介形虫. 北京：海洋出版社. 438
王吴寅, 刘东生, 龙海燕. 2013. 南黄海泥质区YS01A孔有孔虫及其 环境意义. 海洋湖沼通报, 2: 127-134

王琳沝. 2014. 南黄海中部泥质区全新世以来古环境沉积记录及其 对东亚季风的响应. 博士学位论文. 青岛: 中国海洋大学. 80 翁学传, 张以恳, 王从敏, 张启龙. 1989. 黄海冷水团的变化特征. 中 国海洋大学学报(自然科学版), S1: 119-131

夏长水. 2014. 黄海环流变异对主要渔场形成和变迁的影响研究. 北 京: 海洋出版社. 101

向荣, 李铁刚, 杨作升, 阎军. 2003a. 冲绳海槽北部表层沉积物中底 栖有孔虫分布及其与海洋环境的关系. 海洋与湖沼, 34: 671-682 向荣, 李铁刚, 杨作升, 阎军, 曹奇原. 2003b. 冲绳海槽南部表层沉积 中底栖有孔虫分布: 水团和食物供应的共同制约. 海洋学报, 25: $141-148$

薛玉虎. 2014. 中全新世黄海水动力环境特征研究. 硕士学位论文. 天津: 天津科技大学. 61

杨子春, 林和茂, 王圣洁, 李绍全. 1998. 对末次间冰期南黄海古冷水 团沉积的探讨. 海洋地质与第四纪地质, 18: 48-55, 57-59

于非, 张志欣, 刀新源, 郭景松, 汤毓祥. 2006. 黄海冷水团演变过程 及其与邻近水团关系的分析. 海洋学报, 28: 26-34

袁业立，李惠卿。1993。黄海冷水团环流结构及生成机制研究 - I. . 阶解及冷水团的环流结构. 中国科学 B辑: 化学 生命科 学 地学, 23: 93-103

Beardsley R C, Limeburner R, Yu H, Cannon G A. 1985. Discharge of the Changjiang (Yangtze River) into the East China Sea. Cont Shelf Res, 4: 57-76

Berger A, Loutre M F. 1991. Insolation values for the climate of the last 10 million years. Quat Sci Rev, 10: 297-317

Cho K D. 1982. On the influence of the Yellow Sea bottom cold water on the demersal fishing grounds. Bull Korean Soc Fish Tech, 1: 2533

Conroy J L, Overpeck J T, Cole J E, Shanahan T M, Steinitz-Kannan M. 2008. Holocene changes in eastern tropical Pacific climate inferred from a Galápagos lake sediment record. Quat Sci Rev, 27: $1166-1180$

Fang L, Xiang R, Zhao M X, Zhou L P, Liu J G, Zhang L L. 2013. Phase evolution of Holocene paleoenvironmental changes in the southern Yellow Sea: Benthic foraminiferal evidence from core C02. J Ocean Univ China, 12: 629-638

Guan B X. 1994. Patterns and structures of the currents in Bohai, Huanghai and East China Seas. In: Zhou D, Liang Y B, Zeng C K, eds. Oceanology of China Seas. Dordrecht: Springer. 17-26

Hao T, Liu X J, Ogg J, Liang Z, Xiang R, Zhang X D, Zhang D H, Zhang C, Liu Q L, Li X G. 2017. Intensified episodes of East Asian Winter Monsoon during the middle through late Holocene driven by North Atlantic cooling events: High-resolution lignin records from the South Yellow Sea, China. Earth Planet Sci Lett, 479: 144-155 
Hur H B, Jacobs G A, Teague W J. 1999. Monthly variations of water masses in the Yellow and East China Seas, November 6, 1998. J Oceanogr, 55: 171-184

Jia G D, Bai Y, Yang X Q, Xie L, Wei G J, Ouyang T P, Chu G Q, Liu Z H, Peng P A. 2015. Biogeochemical evidence of Holocene East Asian summer and winter monsoon variability from a tropical maar lake in southern China. Quat Sci Rev, 111: 51-61

Kang S, Lim D, Kim S Y. 2010. Benthic foraminiferal assemblage of Seogwipo Formation in Jeju Island, South Sea of Korea: Implication for late Pliocene to early Pleistocene cold episode in the northwestern Pacific margin. Quat Int, 225: 138-146

Kim D, Park B K, Shin I C. 1999. Paleoenvironmental changes of the Yellow Sea during the late Quaternary. Geo-Mar Lett, 18: 189-194

Kim J M, Kennett J P. 1998. Paleoenvironmental changes associated with the Holocene marine transgression, Yellow Sea (Hwanghae). Mar Micropaleontol, 34: 71-89

Kim J M, Kucera M. 2000. Benthic foraminifer record of environmental changes in the Yellow Sea (Hwanghae) during the last 15000 years. Quat Sci Rev, 19: 1067-1085

Klovan J E, Imbrie J. 1971. An algorithm and Fortran-iv program for large-scaleQ-mode factor analysis and calculation of factor scores. Math Geol, 3: 61-77

Kong G S, Lee C W. 2005. Marine reservoir corrections $(\Delta R)$ for southern coastal waters of Korea. J Korean Soc Oceanol, 2: 124-128

Kong G S, Park S C, Han H C, Chang J H, Mackensen A. 2006. Late Quaternary paleoenvironmental changes in the southeastern Yellow Sea, Korea. Quat Int, 144: 38-52

Lei Y L, Li T G. 2016. Atlas of Benthic Foraminifera from China Seas. Beijing: Springer Berlin Heidelberg. 399

Li G, Li P, Liu Y, Qiao L, Ma Y, Xu J, Yang Z. 2014. Sedimentary system response to the global sea level change in the East China Seas since the last glacial maximum. Earth-Sci Rev, 139: 390-405

Li X W, Wang X D, Chu P C, Zhao D L. 2015. Low-frequency variability of the Yellow Sea cold water mass identified from the China coastal waters and adjacent seas reanalysis. Adv Meteor, 2015: $1-14$

Liu J, Saito Y, Kong X H, Wang H, Wen C, Yang Z G, Nakashima R. 2010. Delta development and channel incision during marine isotope stages 3 and 2 in the western South Yellow Sea. Mar Geol, 278: $54-76$

Liu J P, Milliman J D, Gao S, Cheng P. 2004. Holocene development of the Yellow River's subaqueous delta, North Yellow Sea. Mar Geol, 209: 45-67

Mei X, Li R H, Zhang X H, Liu Q S, Liu J X, Wang Z B, Lan X H, Liu J, Sun R T. 2016. Evolution of the Yellow Sea warm current and the Yellow Sea cold water mass since the Middle Pleistocene.
Palaeogeogr Palaeoclimatol Palaeoecol, 442: 48-60

Moreno A, Canals M. 2004. The role of dust in abrupt climate change: Insights from offshore Northwest Africa and Alboran Sea sediment records. Contrib Sci, 4: 485-497

Moy C M, Seltzer G O, Rodbell D T, Anderson D M. 2002. Variability of El Niño/Southern Oscillation activity at millennial timescales during the Holocene epoch. Nature, 420: 162-165

Naimie C E, Blain C A, Lynch D R. 2001. Seasonal mean circulation in the Yellow Sea-A model-generated climatology. Cont Shelf Res, 21: 667-695

Park S, Chu P C, Lee J H. 2011. Interannual-to-interdecadal variability of the Yellow Sea Cold Water Mass in 1967-2008: Characteristics and seasonal forcings. J Mar Syst, 87: 177-193

Park Y A, Khim B K. 1992. Origin and dispersal of recent clay minerals in the Yellow Sea. Mar Geol, 104: 205-213

Rodbell D T, Seltzer G O, Anderson D M, Abbott M B, Enfield D B, Newman J H. 1999. An 15000-year record of El Niño-driven alluviation in Southwestern Ecuador. Science, 283: 516-520

Southon J, Kashgarian M, Fontugne M, Metivier B, Yim W W S. 2002. Marine reservoir corrections for the Indian Ocean and Southeast Asia. Radiocarbon, 44: 167-180

Stuiver M, Reimer P J, Bard E, Beck J W, Burr G S, Hughen K A, Kromer B, McCormac G, Van Der Plicht J, Spurk M. 1998. INTCAL98 radiocarbon age calibration, 24000-0 cal BP. Radiocarbon, 40: 1041-1083

Su Y S, Weng X C. 1994. Water masses in China seas. In: Zhou D, Liang Y B, Zeng C K, eds. Oceanology of China Seas. Dordrecht: Springer. 3-16

Uda M. 1934. The results of simultaneous oceanographical investigations in the Japan Sea and its adjacent waters in May and June, 1932. J Imp Fish Exp Sta, 57-190

Wang D, Huang B Q, Liu X, Liu G M, Wang H. 2014. Seasonal variations of phytoplankton phosphorus stress in the Yellow Sea cold water mass. Acta Oceanol Sin, 33: 124-135

Wang L, Li J J, Lu H Y, Gu Z Y, Rioual P, Hao Q Z, Mackay A W, Jiang W Y, Cai B G, Xu B, Han J T, Chu G Q. 2012. The East Asian winter monsoon over the last 15000 years: Its links to high-latitudes and tropical climate systems and complex correlation to the summer monsoon. Quat Sci Rev, 32: 131-142

Wang P X, Min Q B, Bian Y H. 1985. Distributions of foraminifera and ostracoda in bottom sediments of the northwestern part of the South Huanghai (Yellow) Sea and its geological significance. In: Wang P X, ed. Micropaleontology of China. Beijing: China Ocean Press. 93-114

Xia D S, Jia J, Li G H, Zhao S, Wei H T, Chen F H. 2014. Out-of-phase evolution between summer and winter East Asian monsoons during 
the Holocene as recorded by Chinese loess deposits. Quat Res, 81: 500-507

Xiang R, Yang Z S, Saito Y, Fan D J, Chen M H, Guo Z G, Chen Z. 2008. Paleoenvironmental changes during the last 8400 years in the southern Yellow Sea: Benthic foraminiferal and stable isotopic evidence. Mar Micropaleontol, 67: 104-119
Xu M, Liu Q, Zhang Z, Liu X. 2016. Response of free-living marine nematodes to the southern Yellow Sea Cold Water Mass. Mar Pollut Bull, 105: 58-64

Zhao Y Y, Yang Q Z, Li F Y, Chen Y W. 1990. On the source and genesis of the mud in the central area of the South Yellow Sea. Chin J Ocean Limnol, 8: 66-73

(责任编委: 焦念志) 